\title{
ESCRAVIDÃO E CAPITALISMO NA \\ "PLANTATION" COLONIAL
}

Teresa Cristina Zavaris Tanezini ${ }^{*}$

\section{INTRODUÇÃO}

Este artigo constitui um fragmento de nossa Dissertação de Mestrado, "Os Industriais do Acúcar na "Plantation Colonial", que trata da grande exploração canavieira, caracterizada desde o século XVI. Enquanto uma agroindústria, cujo elemento produtivo fundamental era a fábrica de açúcar.

Durante todo o desenvolvimento do trabalho nossa argumentação foi ao mesmo tempo teórica, analisando o pensamento de Karl Marx de sua obra máxima "O Capital - Crítica da Economia Política" nos 6 volumes, e histórica, reunindo as provas documentais fornecidas pelas fontes primárias e por outros estudiosos.

A colonização do Novo Mundo foi avaliada no contexto das transformações ocorridas na ldade Moderna, não apenas com relação a Revolução Comercial que forjou a formação do mercado mundial, mas principalmente acompanhando o movimento do capital apropriando-se da produção, na medida em que desdobrava-se a divisão social do trabalho. Gradualmente ia-se constituindo o capital industrial (produtivo) que submetia o capital mercantil.

\footnotetext{
"Professora da Universidade Federal de Sergipe. Mestre em Sociologia.
}

Rev. Raizes, Campina Grande, Ano XIII, n' 10, pp.01-18,Dez. 1994. 
A manufatura e a agricultura em larga escala correspondiam ao período manufatureiro (meados do século XVI a XVIII), baseado no trabalhador coletivo. Diversos autores explicaram a adoção da mão de obra escrava. A compulsão ao trabalho naquelas circunstâncias históricas tornava-se o único modo de obter-se força de trabalho na quantidade necessária às "plantations" e esta exigência, dado ao aumento da escala de produção açucareira nas colônias da América, justificou o renascimento da escravidão na civilização ocidental agora sistemática $e$ organizada com um grande e lucrativo negócio.

$O$ que ressaltamos foi que a cooperação sistemática e em larga escala, fundada na divisão do trabalho era a característica primordial da grande exploração canavieira, tanto pela organização da produção dentro da unidade fabril, quanto a nível do conjunto produtivo da "plantation".

Foi a divisão do trabalho que explicou o sucesso do grande empreendimento que reunia grande número de pessoas; a produção do açúcar em tão larga escala; o funcionamento de um mecanismo complexo de operações especializadas em delicadas operações (pois tratava-se de um processo químico) executadas por uma massa de escravos. Após apresentarmos nossas conclusões referentes às relações técnicas de produção, enfocaremos neste artigo um dos aspectos das relações sociais de produção na "plantation": a relação dos proprietários dos meios de produção com os não proprietários, ou seja, com os trabalhadores livres e escravos e nos deteremos na reflexão teórica da possibilidade de um empreendimento agroindustrial capitalista que desde o século XVI que utilizava a força de trabalho escravo.

\section{TRABALHADORES LIVRES E ESCRAVOS}

A força de trabalho é uma propriedade do homem que a possui intrinsecamente como energia física e mental. Portanto, a nosso ver, tanto os trabalhadores livres quanto os escravos eram os efetivos proprietários de sua força de trabalho. Os primeiros, feitores, mestres-deaçucar, banqueiros, soto-banqueiros, purgadores caixeiros e também artesãos, carreiros etc. se dispuseram a empregá-la na fazenda ou no 
engenho mediante um contrato de longo prazo, com altos salários anuais na forma monetária (em réis) como registrou Antonil em 1711, fora a "mesa", (alimentação garantida pela Casa Grande) que poderia ser complementada por pomares, quintais e roçados à volta de suas residências, dentro das propriedades canavieiras.

Outros trabalhadores livres se dispuseram a empregar sua força de trabalho na "plantation" temporariamente, por empreitadas ou por encomendas, com salários em espécies ou na forma monetária. Um mercado livre significava para os patrões a possibilidade de requisitarem a mão-de-obra que lhes fosse proveitosa, e para os trabalhadores a possibilidade de permanecerem enquanto lhes conviessem as condições de trabalho num determinado estabelecimento. $O$ "mercado" de mão-deobra especializada situava-se inicialmente (séc. XVI e XVII) na Europa, mas gradualmente a própria Colônia o foi suprindo, especialmente com os mulatos.

Os escravos obviamente não buscaram trabalho, foram capturados; não venderam sua força de trabalho num mercado livre, foram vendidos pelo tráfico. Os senhores tinham a possibilidade de selecionar a melhor "peça" conforme a demanda específica. Aos assalariados pagavam depois dos serviços prestados, aos traficantes pagavam por uma promessa de serviço, antecipavam capital, faziam investimento.

Os escravos no mercado eram "coisas" expostas, sem manifestação de vontade, porém nas propriedades rurais, passada a fase de adaptação, começavam a perceber que eram "as mãos e os pés dos senhores" na produção da cana $e$ do açúcar.

Se é verdade que os escravos eram, do ponto de vista da rotação do capital, parte adiantada, imobilizada, quer dizer capital constante, do ponto de vista do valor, que é o que nos interessa aqui, eram força de trabalho viva, consciente, capaz de aprender, de adquirir habilidade manual, destreza, rapidez nos movimentos. Sendo assim eram capital variável, capaz de produzir mais valor, que amortizava o capital adiantado e também o custo de produção de sua força de trabalho.

Tanto escravos quanto mestres, carreiros ou feitores eram igualmentc explorados pelo mesmo mecanismo econômico do trabalha- 
dor coletivo e sua jornada de trabalho, do ponto de vista da duração, era idêntica. Em face do valor da produção, tanto os trabalhadores livres quanto os escravos produziam mais valia relativa.

No sistema escravista colonial, a captura e tráfico se deram em função da produção com o objetivo de imobilizar a mão-de-obra, através da adaptação do escravo ao trabalho desenvolvendo sua produtividade, e não - como se deu na escravidão da antigüidade - do aprisionamento sob correntes acompanhado de trabalhos forçados sob chibata.

Para alguns autores, seria pela violência constante e supervisão despótica dos feitores, ou seja, pela coerção extra econômica, que se conseguiria "pôr os negros a trabalhar" sem qualquer recompensa. Para nós, na mesma linha de raciocinio de Stuart Schwartz (1988), os mecanismos extra econômicos do sistema escravista, como o uso da violência legitimada e legalizada, funcionavam no cotidiano mais como ameaça. Eram exemplarmente utilizados, sempre que necessário, como "castigo", ou seja, como "corretivo" para alterar comportamentos, porém não interessavam aos senhores nem as mutilações dos seus escravos, que os impedissem de voltar à produção, menos ainda a sua morte.

O tratamento mais cruel era reservado aos fugitivos, para retirar a esperança de. libertação pela via da auto-iniciativa e para instaurar o clima de "terror" indispensável para restringir a liberdade de locomoção aos limites da propriedade. Os fugitivos eram os únicos escravos acorrentados, enquanto trabalhavam nas fornalhas do engenho, na descrição de Antonil, "porque não se emendavam mais".

Mediante um sistema que combinava castigo e prêmios, os escravos iam sendo condicionados, adaptando-se à disciplina do trabalho colctivo. Os portugueses sabiam "fazer trabalhar seus negros", dizia Adrian Van Der Dussen em 1630 (apud Melo 1981).

Funcionavam no geral os mecanismos de coerção econômica do trabalho escravo, via cooperação simples e complexa no próprio processo de produção da cana $\mathrm{e}$ do açúcar, reforçados pelos prêmios. A "mesa", os subprodutos do açúcar, o salário do final da moagem eram as recompensas dos trabalhadores livres. A ração, os subprodutos do 
açúcar, o roçado, o tempo livre, a não violência, a liberdade relativa ou a libertação total eram as recompensas dos escravos, sendo que alguns que desempenhavam funções mais especializadas, também recebiam gratificação na forma monetária.

Alguns autores analisam o roçado como mais uma forma de extrair sobre trabalho, na medida em que os escravos produziam sua própria subsistência. Para nós prevalece a idéia de prêmio ou incentivo, como diz Schwartz, porque a alimentação básica do conjunto de escravos economicamente ativos era garantida pelas roças da fazenda, cultivadas também em turmas, sob a direção de um feitor, constituindo uma ração, sem dúvida mínima, mas para todos. Daí o poder estimulante da possibilidade de suplementar quantitativa e qualitativamente a alimentação com produtos do roçado que também permitiam algum nível de troca entre os próprios escravos, como farinha e feijão por garapa, por exemplo, bem como alguma poupança monetária mediante venda dos produtos ao próprio senhor a preços abaixo do mercado. $O$ roçado poderia constituir-se, além do mais, num prêmio maior com caráter de semi-"libertação" para os escravos que, após concluírem o período de vida útil no processo de trabalho coletivo, recebiam autorização para instalar-se em mucambos (desocupar a senzala) constituindo família e prestando outros tipos de serviço. As descrições dos cronistas sobre as moradias dos escravos se assemelhavam às dos proletários atuais da "palha da cana".

Os três "P"(s) era a receita do tratamento dos escravos: pau, pão e pano, já tratamos dos dois primeiros aspectos. $O$ "pão" se referia à garantia da subsistência pelo senhor, iniciada pela ração diária de farinha, carne ou peixe seco, complementada na safra/moagem pelo mel de furo e frutas tropicais de estação, coco, pesca e produtos de roçado. A suspensão da ração só ocorria nos castigos. $O$ "pano" se referia à vestimenta; sua exigüidade não trazia maiores sofrimentos, segundo os testemunhos, devido ao clima tropical.

Além do pau, do pão e do pano, os documentos coloniais mencionaram mais um quarto aspecto: a "mezinha", os remédios e a assistência médica prestada por "barbeiros", "veterinários" ou "médicos" providenciados pelo feitor-mor, conforme seu regulamento, 
sem falar dos "raizeiros" negros e índios. A saúde do escravo trabalhador era uma necessidade econômica, para que ele agüentasse a intensidade do trabalho requerido.

Se a captura, o tráfico, a viagem no tumbeiro e o mercado de escravos representavam o momento de destruição cultural, dos laços familiares, de humilhação coisificante, na senzala havia relativa liberdade de reconstrução de relações sexuais (encaradas como promiscuidade) e também afetivas com acasalamentos e até casamentos, que não evoluiam para a construção de famílias para não submeter os filhos à mesma escravidão "do eito", e porque homem e mulher estavam integralmente voltados para a produção; por isso a prática do aborto era intensa. Isso foi se revertendo quando aumentaram as possibilidades de formar pecúlio para comprar a liberdade da mulher, o que dava ao filho nascido "de ventre livre" a condição de homem livre.

Havia também uma relativa liberdade de manifestação cultural, de lazer e de cultos religiosos, no pátio, na capela e na mata. $O$ canto acompanhava o trabalho, as danças assinalavam as festas, o sincretismo religioso era importante mecanismo de adaptação da linguagem simbólica, perpetuando os cultos afros na medida em que os integrava não apenas à religião oficial, mas à sociedade via batismo, sacramentos, irmandades dos pretos.

Na lógica dos senhores escravistas, era preciso combater uma terrivel doença que atingia os escravos resistentes à adaptação - a melancolia, que os abatia tornando-os improdutivos, que os fazia comer terra até morrer.

Finalmente a imobilização da mão-de-obra no engenho ou na fazenda oferecia, como contrapartida à falta de liberdade pessoal, a condição de vida dentro dos parâmetros mínimos que garantissem a reprodução da força de trabalho, a estabilidade e a possibilidade remota mas concreta de obter a liberdade total como concessão do senhor, ou de fazer trocas e formar poupanças para comprar a liberdade e, até mesmo, adquirir escravos.

A Finta de 1654-56 referia-se a vários escravos forros na povoação da Várzea do Capibaribe. As manumissões foram incrementa- 
das até o final do periodo colonial e o escravo libertado tornava-se agregado da propriedade rural ou habitante das povoações e cidades, formando gradualmente o exército industrial de reserva.

A relativa flexibilidade da escravidão colonial no "eito" não chegava ao nível de integração entre escravos domésticos e a família patriarcal (que Gilberto Freyre analisou exaustivamente) mas combinava a coerção extracconômica (repressão efetiva ou latente, papel ideológico quotidiano do capelão na justificação religiosa da escravidão, e na exaltação do trabalho) com a coerção econômica via cooperação para obter alta produtividade.

Flexibilidade que combinava castigo e prêmio para obter adesão voluntária e motivação, que barganhava com o assistencialismo e com concessões, que permitia liberdade relativa dentro das propriedades e acenava concretamente com um fim para a própria escravidão. Isto funcionava do ponto de vista do senhor, como a possibilidade de descomprometer-se com a manutenção de um escravo "improdutivo" após cumprir seu período de vida útil, e, do ponto de vista do escravo como poderoso mecanismo ideológico que o fazia suportar o "jugo" do árduo trabalho escravo, alimentando o sonho de liberdade.

Um mecanismo juridico (alforria, manumissão) the permitia entrar no "mercado de trabalho livre". passando a vender sua força de trabalho para sustentar-se e a sua família e participar da sociedade como pessoa humana (com direitos civis), faltando "apenas" vencer o preconceito racial (resistência social à sua integração como homem livre). Schwartz (1988) menciona "causas" de escravos movidas na justiça contra abusos dos senhores. Independente do resultado ser ou não favorável ao escravo. só o fato de existir este canal de expressão dos cativos junto ao Estado demonstra que a condição de escravo possuía alguns direitos civis. Os escravos urbanos tinham liberdade de locomoção e vendiam sua força de trabalho dividindo os ganhos com o seu senhor, o que demonstra grande flexibilidade da instituição da escravidão e sua compatibilidade com recebimento de salários.

Diversos autores mencionaram a queda da importância numérica dos escravos na primeira metade do século XIX, atribuindo a 
mesma à crise do setor açucareiro do século anterior, mas pode-se refletir também que a "plantation" já havia encontrado suas alternativas para imobilizar mão-de-obra "livre" através dos agregados sob condição.

\section{2 - ESCRAVIDÃO E CAPITALISMO}

Depois que analisamos a "plantation" como capitalista, não em um ou outro aspecto, mas em toda sua estrutura e na lógica do seu funcionamento, inclusive nas suas relações com o mercado internacional, como enfrentamos teoricamente a questão da escravidão e do capitalismo?

A primeira consideração é que não se tratavam de relações patriarcais. Enquanto os escravos domésticos conviviam intensamente com o senhor e sua família no interior da Casa Grande por uma longa existência e mesmo por mais de uma geração, a relação com os escravos "do eito" era, puramente, uma relação de exploração intermediada por feitores, e de caráter despótico.

A distância física da Casa Grande pela separação do espaço produtivo que ocupava quase todo o tempo diário do escravo (em sua longa e exaustiva jornada de trabalho), a distância social dada pelo regime de escravidão que considerava os escravos do "eito" praticamente como animais de trabalho, a alta taxa de mortalidade, o curto período de vida útil (para a produção canavieira), problema resolvido pela aquisição constante de novos escravos, que implicava em certa renovação periódica dos indivíduos, além do absenteísmo do senhor-doengenho, não criavam canais de relacionamento pessoal. Tratava-se de relação puramente mercantil.

Mas resta enfrentar a questão teórica que coloca claramente como condição para a caracterização de relações de produção capitalistas o fato do trabalhador apresentar-se como "duplamente livre". Em primeiro lugar livre, separado dos meios de produção, ou seja, expropriado, e em segundo lugar livre das relações de submissão direta (servidão e escravidão) para poder vender livremente sua própria força 
de trabalho no mercado, trocando-a por um equivalente, o salário, fundamentalmente na sua forma monetária, para que o trocasse igualmente no mercado pelos produtos necessários à reprodução de sua força de trabalho e de sua familia.

Com relação à primeira premissa, tanto os assalariados quanto os escravos eram expropriados, diferentemente dos servos ligados à terra, que possuiam os instrumentos de trabalho e dirigiam sua pequena produção.

Portanto é essa segunda premissa que colocamos em discussão: Quando Marx falou da necessidade histórica de libertação dos camponeses das relações de dominação direta, estava se referindo na Europa diretamente à servidão pela qual os produtores agrícolas estavam subjugados à classe dominante feudal que os explorava, apropriando-se do seu trabalho excedente através da renda fundiária e outras obrigações feudais. A servidão, por conseguinte, constituia-se num entrave para a conformação do modo de produção capitalista, porque essa força de trabalho (e o principal meio de produção - a terra) não estava livre, quer dizer. disponivel para ser explorada pelos burgueses capitalistas.

No caso da escravidão moderna, a força de trabalho era expropriada não apenas dos meios de produção, mas despojada pela escravidão de sua cultura, da sua identidade como pessoa humana, dos seus laços comunitários e familiares. Através do tráfico era colocada total e permanentemente à disposição dos capitalistas, que eram os senhores escravistas, para ser livremente explorada por eles no processo produtivo, de maneira legalizada pela sociedade política (o Estado) e legitimada pela sociedade civil. Aquela fração sui generis da burguesia industrial podia consumir intensamente essa força de trabalho até a morte para aumentar seus lucros.

Voltemos aos termos da segunda premissa: o trabalhador deveria apresentar-se "livre das relações de submissão direta para vender sua própria força de trabalho no mercado..."

Para os economistas clássicos que enunciaram essa lei do desenvolvimento tipicamente capitalista, o tempo não contava: Para 
eles tal premissa era desde sempre e para sempre, ou seja, tinha um caráter a-histórico. Eles partiram de uma situação em que a disponibilidade da mão-de-obra expropriada para os capitalistas já se dava num mercado de trabalho constituído por um excesso de contingente de trabalhadores - o proletariado mais a população supérflua ou exército industrial de reserva. Para eles, a oferta de trabalhadores maior do que a procura pelos capitalistas (aliás, cada vez maior) era o equilibrio "natural" do mercado de trabalho (é claro que do ponto de vista dos patrões capitalistas que eles representavam no plano teórico).

Mas para que se realizasse essa situação ideal que permitia aos capitalistas demitir, desempregar trabalhadores e readmiti-los de acordo com sua conveniência, foi necessário um processo histórico específico que Marx descreveu em dois capítulos do livro I de "O Capital" - "A Chamada Acumulação Primitiva" e "A Lei Geral da Acumulação Capitalista". Neste último ele comenta que o modo de produção capitalista reproduzia em escala ampliada não apenas o capital mas também as relações sociais que lhe serviam de suporte. Logo, desenvolvimento capitalista, acumulação de riqueza tinham como contrapartida necessária a pauperização, a acumulação da miséria.

Vemos aí uma análise do mesmo fato econômico - a compra e venda de força de trabalho no mercado - de duas óticas distintas, uma da economia política clássica na aparência, outra marxista na essência do fenômeno.

Como dissemos anteriormente, apesar dos economistas acharem que essa "livre troca de equivalentes" ocorreu desde sempre, Marx mostrou que ela é fruto de um processo histórico específico. No periodo que estamos analisando, nos tempos modernos, no qual ocorre o processo de expropriação dos camponeses feudais e de sua proletarização, quando não havia ainda a população supérflua, quer dizer, quando a oferta de mão-de-obra era ainda menor do que a procura pelos capitalistas agrários ou manufatureiros, houve compulsão ao trabalho e tentativas legais de imobilização dessa força de trabalho, "forçando" sua disponibilidade ao patrão. 
Nas colônias, a situação era ainda pior. Apesar da expropriação dos indígenas (que liberou praticamente toda a terra e demais recursos naturais), os colonos não conseguiram submeter senão uma pequena parte da população nativa aos trabalhos da agroindústria em grande escala. A maior parte foi trucidada nos combates ou fugiu para áreas inexploradas. Mesmo com os aldeamentos regulares pelos religiosos, os capitalistas não conseguiram imobilizar os índios e torná-los disponiveis para todas as tarefas. Foi necessário desde o início o recurso à importação de mão-de-obra.

Do ponto de vista do empresário da grande produção, foi necessário comprar a força de trabalho num mercado particular - o mercado de escravos. Assim a força de trabalho não era oferecida pelo próprio trabalhador mas por um comerciante e o que era pior, não se pagava essa mão-de-obra aos poucos depois de usufruí-la na forma de salários mas antecipava-se uma grande soma paga ao traficante. Pagava-se pois um alto preço para imobilizar a força de trabalho tornando-a disponível para poder explorá-la livremente, dado às condições históricas especificas em que se encontrava o Novo Mundo.

Nos momentos de grande crise de oferta de mão-de-obra em alguns ramos produtivos europeus ainda durante o século XIX, o recurso a empreiteiros foi utilizado pelos capitalistas agrários e mecanismos diferenciados de imobilização de força de trabalho foram adotados, por exemplo, na mineração onde os trabalhadores habitavam as precárias moradas construídas pelos patrões, dependiam do barracão para se abastecer, eram retidos por dívidas, etc. Isto aliás está embutido nas propostas recentes de agrovilas para trabalhadores rurais.

Retomemos de novo a segunda premissa avançando na análise do seu conteúdo: "...livre das relações de submissão direta para vender sua própria força de trabalho no mercado trocando-a por um equivalente, o salário, fundamentalmente na sua forma monetária para que o trocasse igualmente no mercado pelos produtos necessários à reprodução de sua força de trabalho e de sua familia".

Como acabamos de dizer acima, nem sempre o proletariado europeu recebeu seu salário na forma exclusivamente monetária. Havia 
o salário em espécie, o barracão etc. $O$ que caracterizava o salário não era a sua forma mas o fato de constituir-se apenas no mínimo necessário à reprodução da força de trabalho do proletário e de sua família.

$O$ processo histórico de desenvolvimento capitalista deteriorou de tal forma as condiçốes de vida que criou uma massa da população disposta a trabalhar exaustivamente só por esse mínimo por falta absoluta de alternativas, mínimo que descia abaixo de qualquer parâmetro de dignidade humana, e, nas crises, quando havia super oferta de mão-de-obra, caía abaixo do mínimo vital.

$\mathrm{Na}$ "plantation" colonial, além de adiantar grande soma ao traficante, o capitalista tinha que negociar diretamente com o trabalhador escravo sua disposição pessoal e intransferível para o trabalho. Primeiramente o patrão lhe garantia uma ração alimentar mais panos, "mezinhas" (remédios e assistência médica) e habitação, ou seja os meios indispensáveis à reprodução de sua força de trabalho individual (já que o escravo e a escrava eram sustentados pelo senhor, independentemente de se acasalarem ou não). Além disso havia, como vimos, certa margem de barganha para a aquisição de outras vantagens materiais: prêmios ligados à suplementação alimentar (como a garapa e o roçado) ou de aumento do tempo livre (a custa de maior intensificação do trabalho por produção). Posteriormente "o jornal" ou certa poupança monetária proveniente da venda dos produtos do roçado. Os escravos nestas circunstâncias não estavam totalmente excluídos do mercado interno e alguns chegaram até a possuir seus próprios escravos. A comparação do nível de vida de proletários e escravos, dependendo das variações conjunturais no caso dos primeiros, mostraria um quadro precário para ambos.

Nas relações de produção tipicamente capitalistas, os proletários recebiam o salário depois que haviam produzido trabalho necessário (do qual o salário era a contrapartida) e trabalho excedente (apropriado gratuitamente pelo patrão, sem qualquer contrapartida), o que produzia a ilusão de que correspondia a uma recompensa equivalente a todo trabalho realizado, e portanto, escondia a extração da mais valia. A relação econômica de aparente igualdade, de troca de equivalentes no mercado, fetichizada pelo salário, escondia a relação social 
profundamente desigual entre o proprietário dos meios de produção e os vendedores de forçà de trabalho.

O caráter despótico das relações de trabalho era o resultado inevitável do antagonismo entre o explorador e o objeto dessa exploração. E as péssimas condições de trabalho retratavam a "frugalidade", o "espírito de economia" dos capitalistas, ironizava Marx, quando se tratava dos trabalhadores, devido à ganância de aumentar mais e mais os lucros.

$\mathrm{Na}$ "plantation" canavieira, os trabalhadores escravos produziam, além do trabalho necessário para a reprodução de sua força de trabalho, o trabalho excedente apropriado pelo patrão. Produziam mais valia absoluta e relativa na brutal e aberta exploração.

Diante da possível argumentação de que, no caso dos proletários, os mecanismos de compulsão ao trabalho eram exclusivamente cconômicos, em oposição ao caráter exclusivamente extra-econômico do cscravismo marcado pela violência, chamamos à reflexão de que nenhuma das dụas relações de trabalho tinha esse caráter exclusivo: tanto nas relações escravistas da "plantation", quanto nas relações tipicamente capitalistas assalariadas na Europa, nos tempos modernos, o que ocorreu foi não apenas a compatibilidade mas a combinação perfeita de mecanismos econômicos e extra-econômicos, dialeticamente falando.

$\mathrm{Na}$ "Chamada Acumulação Primitiva do Capital", Marx demonstrou que a natureza do capitalismo não é idílica e mostrou a violência do processo de expropriação e formação do proletariado compelido ao trabalho pelo concurso da coerção extra-econômica materializada na força do Estado expressa em leis sanguinárias e na ação repressiva direta da polícia e indireta de diversas instituições, inclusive assistenciais.

$\mathrm{Na}$ "plantation" moderna, a coerção extra-econômica - a instituição da escravidão com seus aspectos de violência física direta, ou como ameaça latente, de discriminação racial e social, de opressão cultural, religiosa, quer dizer, ideológica foi, como vimos, articulada com mecanismos econômicos nas modernas relações de trabalho. Entre 
elas, destacamos a divisão do trabalho que movimentou o trabalhador coletivo, bem como o sistema de trabalho por tarefa, por produção. Não se trata portanto de coerção extra-econômica como oposição ao econômico, caracterizando relações de produção atrasadas (as escravistas) versus relações de produção modernas (as assalariadas). Quando Marx conceituou a subsunção formal do trabalho ao capital, ou seja, que o capital se utiliza de qualquer forma de relação de produção, se aproveita do produto sem interferir diretamente no modo de produção, ficou claro para muitos que aí estava a solução teórica para o escravismo colonial.

Porém, no caso da escravidão na agroindústria açucareira colonial, insistimos que não se tratava disso, mas de subsunção real de trabalho ao capital dentro do processo produtivo.

Ao longo de toda sua obra - "O Capital" - Marx procedeu à crítica da economia política clássica passo a passo, de forma minuciosa, colocando em cheque cada um dos seus argumentos básicos. Com relação a essa premissa que estamos analisando, ou seja, a compra e venda de força de trabalho livre como troca de equivalentes, ele questionou justamente o "caráter livre" do trabalhador europeu e a pretensa "igualdade da relação" e concluiu que se tratava de escravidão disfarçada, tratando inúmeras vezes o proletário como escravo submetido ao patrão.

A escravidão sem disfarces das colônias, apesar da diferença na forma da relação (social, jurídica), tinha identidade na essência da dominação e exploração dos expropriados. A luta coletiva dos trabalhadores assalariados nas suas associações de classe converteu-se numa guerra sem quartel contra a tentativa de submissão total por parte dos capitalistas. Os escravos também tiveram suas próprias formas de resistência, inclusive coletiva, que não pudemos desenvolver neste trabatho...

Marx concluiu o livro I - O Processo de produção do capital após analisar o processo histórico da "Lei geral da acumulação capitalista", da "Chamada Acumulação Primitiva" e da "Teoria Moderna da Colonização", dizendo (no último parágrafo): 
"Interessa-nos apenas o segredo que a economia do Velho Mundo descobriu no Novo e proclamou bem alto: o modo capitalista de produção e de acumulação, e portanto a propriedade privada capitalista exigem como condição existencial o aniquilamento da propriedade privada baseada no trabalho próprio, isto é a expropriação do trabalhador". (Marx, LI, vol.2, 1980:894).

Se acompanharmos o raciocínio de Marx, a segunda premissa foi lógica e historicamente superada, restando apenas a primeira premissa. Por isso afirmamos como outros autores: Beiguelman (1976), Mendes e Figucira (1977) etc., que o escravo, que analisamos restritamente na economia canavieira moderna, era um proletário e que as relações de produção nessa estrutura agroindustrial eram de natureza capitalista.

Apesar de constituir-se numa anomalia, os senhores-deengenho, e os plantadores de cana escravistas eram capitalistas industriais (empresários da produção), sendo os lavradores mais especificamente capitalistas agrários e os senhores das manufaturas os industriais do açúcar na "plantation" colonial.

\section{CONCLUSÕES}

A escravidão sistemática moderna foi um recurso para garantir a compulsão ao trabalho e a imobilização dos trabalhadores na "plantation". Não devemos correlacionar de forma absoluta e exclusiva a força de trabalho na "plantation" canavieiro com a escravidão. Sem negar a importância dos escravos que eram "as mãos e os pés dos senhores", chamamos a atenção para o fato de que havia uma gama complexa de relações sociais de produção na agroindústria açucareira. De fato, senhores e escravos constituíam os pólos das relações de exploração no período colonial; contudo seria uma simplificação se nos reduzissemos a isso na análise das contradições da época.

Tanto entre os proprietários dos meios de produção diretamente ligados à "plantation" canavieira (senhores-de-engenho e lavra- 
dores) quanto entre os não proprietários, havia vários segmentos ou frações. Dentre aqueles que compunham a força de trabalho nos engenhos, os escravos eram os trabalhadores manuais (produtores diretos) enquanto os homens livres e assalariados constituiam todos os trabalhadores intelectuais (produtores indiretos), bem como a mão de obra especializada dentro da hierarquia dos produtores diretos. Ambos os contingentes de trabalhadores eram indispensáveis na divisão do trabalho da "plantation" canavieira.

A força de trabalho, qualquer que fosse sua forma jurídica nas relações sociais de produção (asssalariada ou escrava) já existia como mercadoria totalmente disponivel para a exploração capitalista (subsunção real do trabalho ao capital). Se o escravo era capital constante, do ponto de vista da rotação do capital (adiantado ao traficante), do ponto de vista que nos interessa, do valor, era capital variável, produtor de mais valia absoluta (prorrogação temporal da jornada de trabalho) e especialmente de mais valia relativa (pela cooperação). Portanto mais do que pela extração da mais valia absoluta, o lucro do empresário colonial era obtido pela mais valia relativa.

A estrita disciplina conseguida pelo caráter despótico da superintendência do trabalho (papel repressivo dos feitores que era também econômico) característica das grandes explorações canavieira não deve ser atribuída exclusivamente ao regime escravista, pois se aproximava segundo Karl Marx, dos grandes empreendimentos manufatureiros europeus.

Se os senhores escravistas conseguiram pelo tráfico obter trabalhadores e pelo escravismo imobilizá-los nos estabelecimentos rurais, para obter sua disposição voluntária para o trabalho ao ritmo requerido, precisavam negociar individualmente e até coletivamente. Além do iso da violência potencial ou efetiva funcionavam os mecanismos internos ao próprio processo de trabalho (cooperação simples e complexa), a garantia das condições de reprodução da força de trabalho (moradia, ração, vestimenta, assistência "médica") e uma série de prêmios. Tempo livre, suplementação alimentar, roçado, possibilidade de ascensão na hierarquia produtiva, liberdade relativa nos limites da propriedade e liberação via manumissões e alforrias. 
A nosso ver, as fontes históricas comprovaram nossa hipótese de que a "plantation" canavieira colonial era uma agroindústria capitalista com escravos. No entanto a aceitação dessa conclusão final passa pela rediscussão teórica sobre o contexto da Idade Moderna (vide Tanezini, 1994) e sobre as premissas do modo de produção capitalista que descobrimos neste artigo cuja reflexão nos levou a conclusão de que tanto os trabalhadores livres quanto escravos da "plantation" eram na essência, proletários assim como Marx desnudou a escravidão disfarçada dos proletários europeus sob o fetiche do salário e da livre troca de equivalentes.

O que nos importa é prosseguirmos discutindo, por isso reafirmamos com Carlos Guilherme Mota:

"A discussão de velhos documentos pode trazer novas interpretações e hipóteses, novas formulações de velhos problemas". Isso é essencial para o avanço dos debates sociológi$\cos$.

\section{BIBLIOGRAFIA"}

BEIGUELMAN, Paula. "A Destruição do Escravismo Capitalista" in Formação Política do Brasil 2a. ed. São Paulo: Pioneira, 1976.

BENCI, Jorge. Economia Cristã dos Senhores no Governo dos Escravos (1700), São Paulo: Grijalbo, 1977.

Finta para o Casamento da Rainha da Grã Bretanha e a Paz na Holanda (1964-66) in MELLO, José Antônio G., Separata da Revista IAHGPE vol. LIV. 1981.

MARX, Karl. O Capital - Crítica da Economia Politica. Livro I e III, vol. 1 a 6, Rio de Janeiro: Civilização Brasileira, 1980.

"Para uma bibliografia detalhada sobre o tema, ver nossa disscrtação de mestrado aqui citada. 
MELO, Josemir Camilo de. "Crítica de uma História Crítica" in Caderno Brasil em Debate n. 1. Campina Grande: UFPB/CH - Depto. de Sociologia e Antropologia, 1981 . p. 47-50.

MENDES, Claudine M. M. e FIGUEIRA, Pedro A. "Estudo Preliminar: O Escravismo Colonial" in BENCI Jorge. Economia Cristã dos Senhores no Governo dos Escravos (1700), São Paulo: Grijalbo, 1977.

SCHWARTZ, Stuart B. Segredos Internos - Engenhos e Escravos na Sociedade Colonial 1550-1835. São Paulo: Cia. das Letras/CNPq, 1988.

TANEZINI, Theresa Cristina Zavaris. Os Industriais do Açucar na "Plantation" Colonial. Campina Grande: Dissertação de Mestrado em Sociologia, UFPB/CH, 1994. 